\title{
Recent Developments in Cyclotron Technique
}

\author{
By Dr. W. B. Mann, Imperial College, London
}

\begin{abstract}
A $\mathrm{T}$ Berkeley, California, the first cyclotron to $A$ be built for the purpose of medical and biological research is nearing completion. In Great Britain it still remains a matter for debate as to whether the immediate expenditure on the construction of a medical cyclotron would be justified or whether it would, perhaps, be better policy to await the outcome of the research which has already been started in Berkeley.

The underlying principles of the cyclotron have already been adequately described in these columns by- Prof. J. Chadwick (Nature, 142, 630 ; 1938). It will therefore be the purpose of this article to try to enumerate some of the developments that have been made during the last few months.

Perhaps the most important of these developments has been the completion in Berkeley of an investigation into the possibility of using the very large currents circulating within the 'dees' of the cyclotron for the purpose of preparing artificially radioactive material. In the preparation of radioactive substances, either for therapeutic or for indicator purposes, it is important to obtain large yields. An increase in yield may be achieved in two ways: by using higher intensities, or, in the case of proton or deuteron bombardment, by the use of particles of higher energy.
\end{abstract}

In the latter case we are tacitly accepting the fact that the energies available are still considerably less than the energy corresponding to the top of the potential barrier of the bombarded nucleus, and that the yield is still rapidly increasing with increasing energy of the bombarding particle.

The purpose of the new cyclotron at Berkeley is to increase both the current and the energy of the emerging beam. With this cyclotron it is hoped to obtain deuterons with energies corresponding to accelerations in the neighbourhood of fifteen million electron volts. In the meantime, however, every effort is being made to increase the yields of radioactive products by using the large currents available within the 'dees' of the present cyclotron at Berkeley.

Prof. E. O. Lawrence had suspected the existence of large currents of circulating ions within the 'dees' and these suspicions were confirmed by the observations of R. R. Wilson, of the Radiation Laboratory, which were reported last August at the meeting at San Diego of the American Physical Society. It was found that in the case of deuterons, the ion current circulating within the 'dees' was of the order of one milliampere, the energies of the deuterons ranging from 6 to 9 million electron volts. Only some 10 per cent of the available current was, however, being withdrawn by the deflector and used in the target chamber.

A paper published by R. R. Wilson and M. D. Kamen last December describes the technique whereby these large currents of high-energy ions may be utilized in the preparation of radioactive phosphorus and iron. Previously, as has been described by F. N. D. Kurie, radioactive phosphorus had been prepared by bombardment of red phosphorus in an atmosphere of helium, the bombardment chamber being separated from the vacuum chamber of the cyclotron by means of a thin iron window, which was itself rendered radioactive by the deuterons passing through it. Thus both radioactive phosphorus for therapeutic purposes and radioactive iron for indicator experiments were produced simultaneously.

Wilson and Kamen have used instead iron phosphide for bombardment and have inserted this, mounted upon a water-cooled copper plate, between the 'dees', through the south window of the Berkeley cyclotron; the design and disposition of the Berkeley cyclotron having become something of a prototype, no further explanation with regard to the point of the compass is, perhaps, necessary. They found that they were able to obtain currents of incident deuterons of 150-200 microamperes, and at the same time the beam drawn by the deflector from the 'dees' and arriving in the target chamber was decreased by only 10 per cent. By inserting the target farther between the 'dees', incident ion currents of more than six hundred microamperes were obtained.

Using this technique, Wilson and Kamen have succeeded in obtaining ten millicuries of radio active phosphorus in the course of a day.

A further advantage of the use of internal targets is derived from the fact that the ion current density is higher within the 'dees', and thus for a given yield it is necessary to expose a much smaller area of target than in the case of bombardment in the target chamber. Thus the ratio of radioactive to inactive phosphorus is enhanced, a definite advantage for therapeutic purposes where it may not be desirable to administer large quantities of inactive phosphorus. Wilson and Kamen are confident that specimens of several millicuries per milligram of phosphorus can easily be prepared. 
The possibility of using neutron irradiation for the treatment of cancer has been one which has long attracted the attention of Prof. Lawrence, and two years ago, in collaboration with his brother, Dr. John Lawrence, and Mr. P. C. Aebersold, he published the results of a comparative study of the effects of X-rays and neutrons upon healthy and malignant tissue. From these it appeared that, for a given lethal dose with respect to normal healthy tissue, neutrons were quite as effective as X-rays in destroying malignant cells and indeed might even be more efficacious to the extent of some 20-30 per cent. These experiments were carried out on mice, using transplanted sarcoma tumours. The results were sufficiently encouraging for experiments to be planned on a clinical scale, and the new cyclotron was designed with this in view.

Before such experiments could be carried out, however, it would be necessary to obtain a collimated beam of fast neutrons which could be directed upon that locality which it was desired to irradiate. The satisfactory solution of this problem has been reported by Aebersold and Prof. Gladys A. Anslow at the New York meeting of the American Physical Society last February. Essentially, the fast neutron beam was obtained by means of an air channel through a water tank, the depth of water being sufficient to reduce the velocities of the neutrons and also appreciably to absorb them. A certain intensity of unabsorbed slow neutrons will, however, not be detrimental, since the biological action of neutrons is chiefly by reason of the heavy ionization produced by the proton recoils from fast neutrons. In order to eliminate gamma-radiation originating in both the water tank and the source, Aebersold and Anslow surrounded their channel and covered the outside walls of the water tank with lead and filtered the beam of fast neutrons through a slab- of the same material. With the beam so obtained clinical treatment has already begun in Berkeley.

Further recent developments in cyclotron technique include an important contribution by $\mathrm{L}$. W. Alvarez who, very ingeniously, by modulation of the cyclotron beam, has been able to produce monochromatic beams of neutrons of thermal energies. The method is essentially similar to that which has been developed independently by G. E. F. Fertel, P. B. Moon, G. P. Thomson and C. E. Wynn-Williams, and which was the subject of a recent letter in NAture $(142,829$; 1938). Bursts of neutrons were produced, in the former case by modulation of the radio-frequency input to the cyclotron, and in the latter by modulation of the current in the ion source of a $300 \mathrm{kv}$. deuteron discharge tube. The resolution which has been obtained by Alvarez is not, however, so sharp as in the experiments with the discharge tube, a difference which can probably be ascribed to the fact that, in the case of the cyclotron, instead of a short sharp pulse of voltage being applied to the plates of the oscillator, modulation was effected by the use of 60-cycle A.c. after half-wave rectification. Under these conditions Alvarez reports that the cyclotron beam was incident upon the target for 25-30 per cent of each cycle, whereas in the case of the experiments of Fertel, Moon, Thomson and Wynn-Williams, the duration of the neutron pulse was limited to only 10 per cent of the cycle.

Alvarez has, however, quite adequately demonstrated the potentialities of his method, and any increase in resolution is probably merely a matter of experimental refinement if, and when, it may be required.

A question which has aroused some interest, although it has as yet little practical significance, is the difficulty which will arise when the energies of the ions produced in the cyclotron shall be so great as to cause a breakdown in the resonance condition, due to the relativistic increase in mass of the ions at velocities comparable with that of light. A deuteron having an energy of fifteen million electron volts or an alpha-particle having twice that energy will be travelling with velocities of a little more than a tenth of the velocity of light. The consequent increase in mass of about one per cent, due to relativity, will cause an increase in the time taken for a particle to describe the semi-circular path within the 'dees'. It will therefore tend to lag behind the electric field and will be lost from the beam.

By effecting a suitable increase in the magnetic field at large radii, the path of the ion can be decreased to such an extent that it will arrive in phase with the electric field, but such a magnetic field would necessarily have a defocusing effect upon the beam. In a recent paper, L. H. Thomas has suggested that the magnetic field should be made, not only to increase with radius, but also to vary periodically along the path of the ion. This latter variation in the magnetic field introduces a further focusing effect which will partially counteract the defocusing effect due to the increase of magnetic field at large radii, necessary to compensate for the relativistic increase in mass of the ions. Thomas shows that by this expedient it will be possible to attain to energies where the relativity effect is already appreciable.

In deciding between the relative merits of radium, $\mathrm{X}$-rays and a cyclotron for medical purposes, there is a natural tendency to count the cost and to calculate possible yields of radioactive materials in terms of interest on capital expended. Already sources of radioactive sodium have been prepared 
in Berkeley with a strength of several hundred millicuries using the ordinary technique of bombardment with deutrons in the target chamber; radioactive sodium, in the process of decaying to magnesium in the ground state, emits a gamma-ray of such energy as may dispose of the need for radium for some purposes. This, with the results of the investigations into the yields using internal targets, and the possibilities of neutron irradiation of malignant tissue, should be an added stimulus to those who are in favour of the immediate construction of a cyclotron for medical purposes in Great Britain, believing that active research alone, with the most recent techniques available, is the necessary preliminary to any further progress in the treatment of cancer.

There are now some twenty-six cyclotrons, either operating or under construction, in various parts of the world. At Berkeley there are two cyclotrons, one belonging to each of these two eategories. In addition, cyclotrons are running, or have been running, at the following places: Ann Arbor, Michigan; Cambridge ; Copenhagen ; Ithaca, New York (Cornell) ; Leningrad ; Princeton; New York (Columbia); Rochester, New York; Swarthmore, Pennsylvania (The Bartol Foundation of the Franklin Institute); Tokyo; Urbana, Illinois.

Cyclotrons are also under construction at Birmingham ; Bloomington, Indiana ; Cambridge, Massachusets (Harvard University and Massachusets Institute of Technology); Chicago ; Columbus, Ohio ; Lafayette, Indiana (Purdue); Liverpool ; Montreal (McGill); New Haven, Connecticut (Yale) ; Paris ; Seattle, Washington ; Stockholm.

The conclusion of this article on the cyclotron would, indeed, be inappropriate without a tribute to Prof. Ernest Lawrence, through whose imagination and experimental skill this valuable tool has been placed in the hands of the experimental physicist.

\section{North Rona: a North Atlantic Island*}

\section{By Dr. F. Fraser Darling}

$\mathrm{M}^{\wedge}$ AN has such little interest in Rona that this island of less than half a square mile has disappeared from many maps of Scotland. It lies about forty-five miles north-east of the Butt of Lewis and north-west of Cape Wrath. The island is completely rockbound, the cliffs varying from a few feet to 355 feet in height. The continual Atlantic swell makes landing difficult and often impossible.

Rona is a northern outpost of the Hebridean hornblende gneiss intersected by several veins of pegmatite. Botanically, the island is distinct from the Hebrides. The northern end of Lewis is a vast peat bog which grows a characteristic herbage complex dominated by heather (Calluna). But there is no peat on Rona. The rock is covered with a thin layer of soil held together with a good turf of Yorkshire fog (Holcus), bents (Agrostis), sheeps' fescue (Festuca). Sedges (Carex) are rare on Rona, occurring only to the west of the ancient village site, where the turf has been cut for fuel hundreds of years ago. There are no permanent pools of fresh water on Rona. A well for seepage has been chiselled in the solid rock at the edge of the cliff in Poll Heallair on the south side of the island and it holds about ten gallons.

\footnotetext{
* Substance of a Friday evening discourse delivered at the Royal Institution on January 20.
}

The drier rocky places are covered with a wealth of sea pink (Statice) and buckshorn plantain (Plantago); the cliff edges, heavily manured by the summer population of birds, grow luxuriant sprays of scurvy grass (Cochlearia), some sheep sorrel (Rumex) and mayweed (Matricaria). The village area with its lazy beds grows wild white clover (Trifolium) on the dry banks of conserved soil, and in the immediate vicinity of the ancient dwellings, silverweed (Potentilla) almost crowds out everything else. There is no bracken, fern or spleenwort, and few of those flowers which make the northern lands gay in May and June.

The whole of Rona is washed by salt spray in winter gales, but the northern peninsula of Fianuis is often impassable under a continuous driven cloud. Only plants with a high tolerance of salt can grow there-annual poa grass (Poa), sea pink, sea milkwort (Glaux) and chickweed (Cerastium).

So far as we know, St. Ronan was the first human inhabitant of Rona, in the eighth century A.D. He moved to Rona from Eoropaidh at the north end of Lewis and adopted the name of the island as his own. Thus we gather that Rona, ron-y, has been the island of seals for a very long period. The cell of St. Ronan still remains in a fair state of preservation, and I have done some 